\title{
Badanie własności złączy ze stali S690QL spawanej metodą MAG
}

\section{Testing of properties of GMA welded S690QL steel}

\section{Streszczenie}

Przedmiotem badań były złącza doczołowe ze stali S690QL o grubości $10 \mathrm{~mm}$, spawane metodą MAG. Wykonano analizę metalograficzną złączy, określono rozkłady twardości w obszarze spoiny, przeprowadzono statyczna próbę rozciągania złączy poprzecznych i zbadano ich udarność. Uzyskane spoiny posiadały niezgodności spawalnicze których wymiary graniczne odpowiadały poziomowi jakości D. Maksymalna twardość złącza w strefie SWC wyniosła 317 HV10, minimalny kąt gięcia próbki wyniósł $90^{\circ}$. Wytrzymałość na rozciąganie wyniosła $853 \mathrm{MPa}$.

Słowa kluczowe: stal S690QL, badania wytrzymałościowe, spawanie MAG

\section{Abstract}

The subject of the research were GMA welded butt joints made of $10 \mathrm{~mm}$ thick S690QL steel. The metallographic analysis of joints was made, hardness in the joint area was measured, the static tensile test and impact test of transverse joints conducted. Joints contained imperfections with size at the D quality level. Maximum hardness of the joint in the HAZ was $317 \mathrm{HV} 10$, minimum angle of specimen bending was $90 \mathrm{deg}$. The measured tensile strength was $853 \mathrm{MPa}$.

Keywords: steel S690QL, strength tests, welding GMA

\section{Wstęp}

Spawanie było wykonane drutem litym niskostopowy gat. G 65 4M Mn3 Ni1CrMo według EN ISO 16834, firmy Lincoln Electric w osłonie gazu $\mathrm{Ar}+18 \% \mathrm{CO}_{2}$, według ISO 14175 - M21 - ArC-18\%.

Energia liniowa dla warstw wypełniających wynosiła $0,50 \mathrm{~kJ} / \mathrm{mm}$, a dla warstwy podpawania $0,24 \mathrm{~kJ} / \mathrm{mm}$. Spawanie przeprowadzono na zrobotyzowanym stanowisku MOTOMAN EA1900. Spoinę wykonano w trzech ściegach z podpawaniem po szlifowaniu grani spoiny. Płytę próbną pokazano na rysunku 1.

\section{Pomiary twardości}

Pomiary twardości wykonano na mikro twardościomierzu "Fritz Heckert” Karl - Marx-Stadt, przy obciążeniach 98 N. Układ linii pomiarowych na przekroju spoiny pokazano na rysunku 2, a wyniki pomiarów twardości przedstawiono na rysunkach $3 \div 5$.

Twardość materiału rodzimego wyniosła ok. 260 HV10. W strefie wpływu ciepła twardość nieco wzrosła do ok. 320 HV10. Można też zauważyć, że twardość spoiny (ok. 240 HV10) jest nieco mniejsza niż twardość materiału spawanej stali.

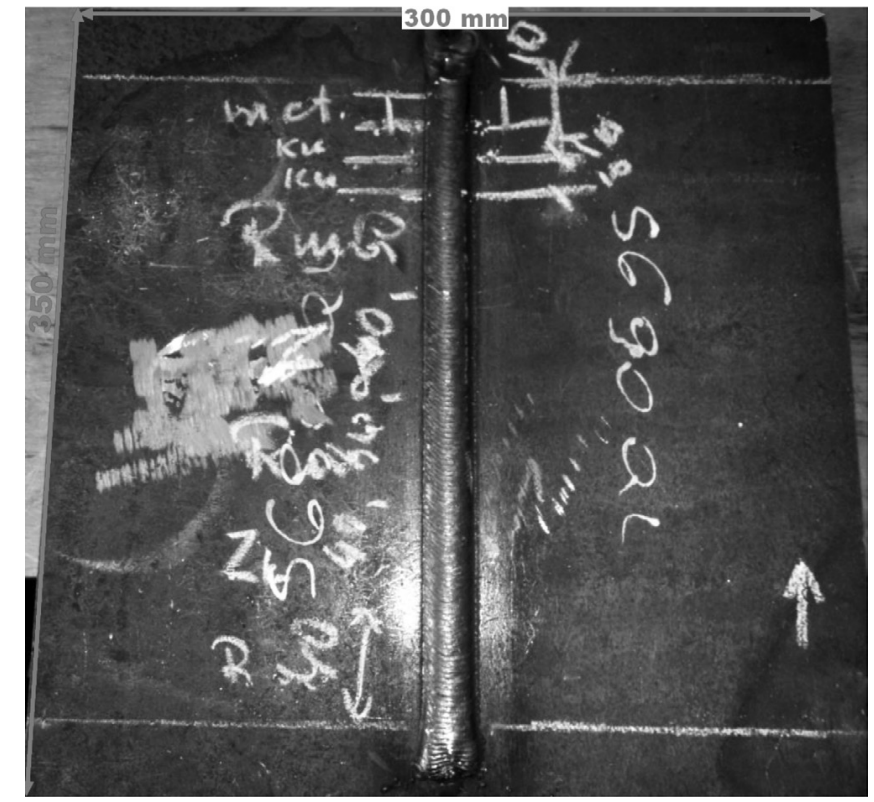

Rys. 1. Złącze próbne wykonane na elementach blachy ze stali S690QL

Fig. 1. Test joint made of S690QL steel plate

Dr inż. Artur Lange, dr inż. Piotr Białucki, dr inż. Wiesław Derlukiewicz, prof. dr hab. inż. Andrzej Ambroziak, mgr inż. Tomasz Mach, dr inż. Maciej Zwierzchowski - Politechnika Wrocławska. 


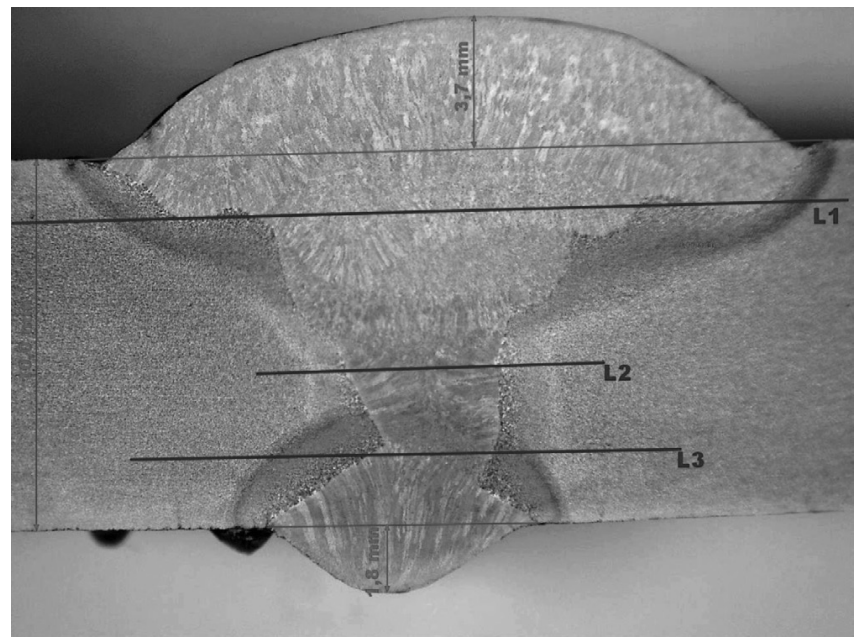

Rys. 2. Próbka do pomiaru twardości z naniesionymi liniami pomiarowymi

Fig. 2. A specimen for hardness measurement with measurement lines

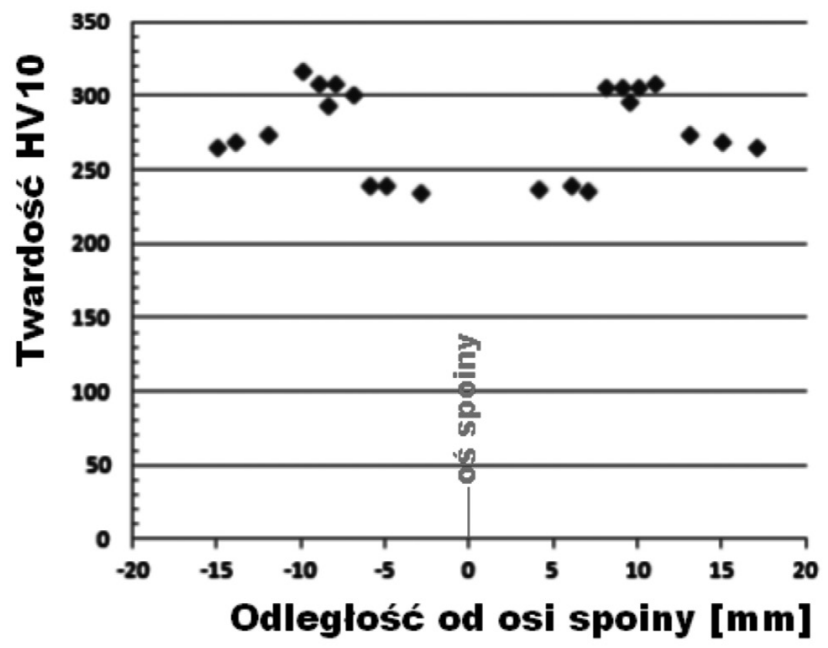

Rys. 3. Zależność twardości złącza od umiejscowienia odcisku względem osi spoiny dla pierwszej linii pomiarowej

Fig. 3. Dependence of the hardness and the distance of the indentation from the joint axis for the first line

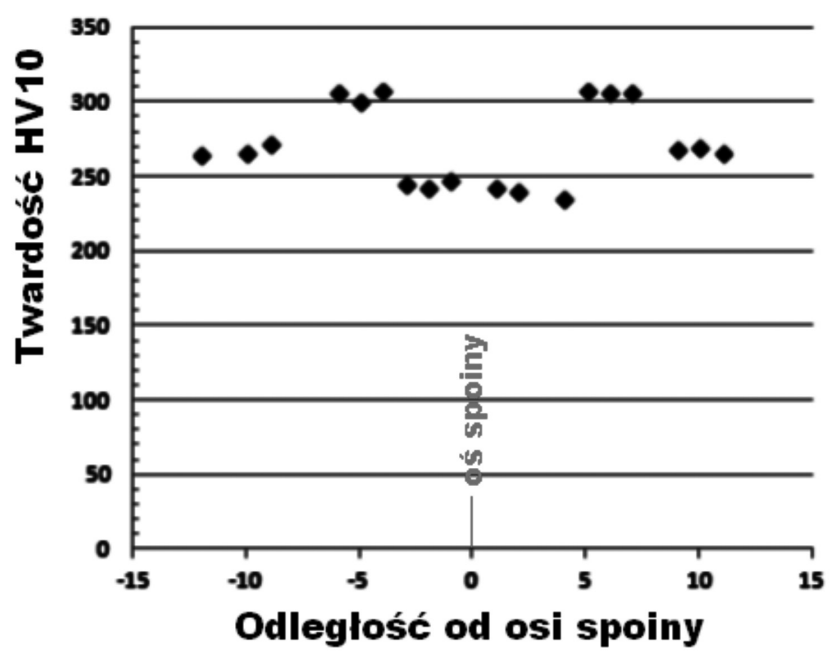

Rys. 4. Zależność twardości złącza od umiejscowienia odcisku względem osi spoiny dla drugiej linii pomiarowej

Fig. 4. Dependence of the hardness and the distance of the indentation from the joint axis for the second line

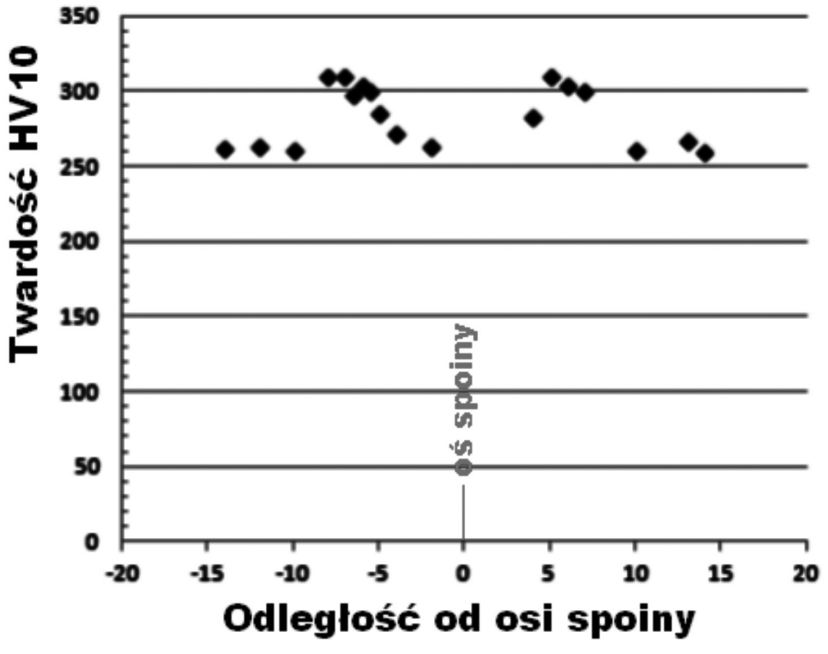

Rys. 5. Zależność twardości złącza od umiejscowienia odcisku względem osi spoiny dla trzeciej linii pomiarowej

Fig. 5. Dependence of the hardness and the distance of the indentation from the joint axis for the third line

Według PN-EN ISO 15614-1 dopuszczalne maksymalne twardości w złączach spawanych ze stali 690QL, która należy do 3-tej grupy, podgrupy 3.1, stali sklasyfikowanej wg CR ISO 15608, wynoszą 450 HV10 w stanie nieobrobionym cieplnie po spawaniu, a po obróbce cieplnej twardość ta nie powinna być większa niż 380 HV10. W badanym złączu bez obróbki cieplnej po spawaniu, maksymalna twardość wyniosła 318 HV10.

\section{Statyczna próba rozciągania złączy, udarność i próba zginania}

Badania wytrzymałości na rozciąganie wykonano według PN-EN ISO 4136 na próbkach poprzecznych pobranych ze złącza próbnego. Rozciąganie przeprowadzono na maszynie wytrzymałościowej MTS 810 na zakresie pomiarowym $0 \div 250 \mathrm{kN}$. Przykładowy wykres z próby rozciągania oraz wygląd zerwanej próbki pokazano na rysunkach 6 i 7. Porównanie własności stali i złączy spawanych metodą MAG przedstawiono w tablicy I. Jak można zauważyć na rysunku 7 przełom próbki nastąpił w materiale rodzimym stali. Wytrzymałość złącza wyniosła $853 \mathrm{MPa}$.

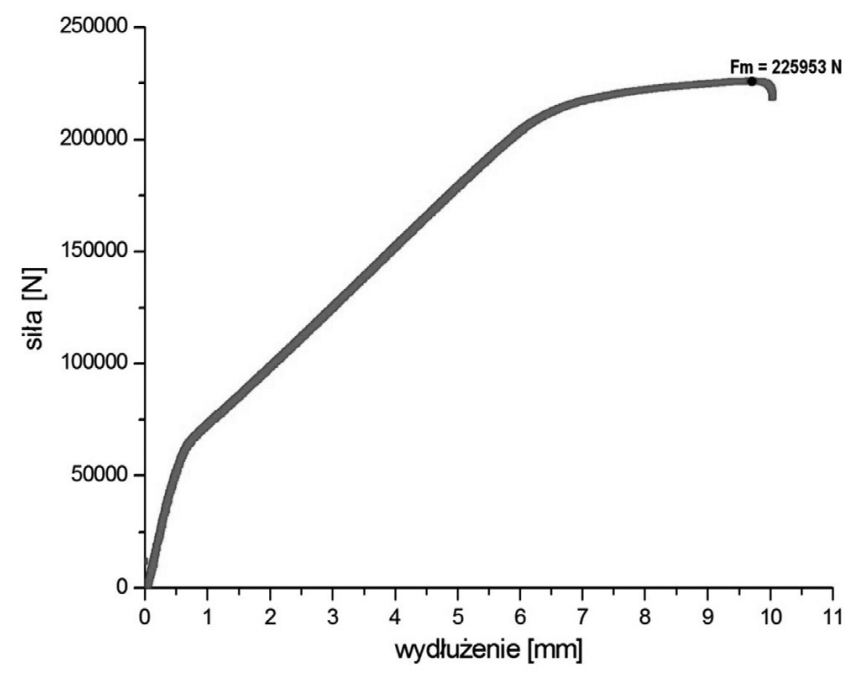

Rys. 6. Wykres rozciągania doczołowego złącza poprzecznego ze stali S690QL spawanego metodą MAG

Fig. 6. Curve of elongation of the GMA welded S690QL transverse butt joints 
Tablica I. Własności wytrzymałościowe ze stali $690 Q \mathrm{~L}$ oraz złączy spawanych metodą MAG

Table I. Strength properties of steel S690QL and joints welded by MAG method

\begin{tabular}{|l|c|c|c|}
\hline \multicolumn{1}{|c|}{ Próbka } & $\mathrm{R}_{0,2 \mathrm{~min},}[\mathrm{MPa}]$ & $\mathrm{R}_{\mathrm{m}},[\mathrm{MPa}]$ & Norma \\
\hline Stal & 690 & $770 \div 910$ & PN-EN ISO \\
\hline Złącze spawane & - & 853 & - \\
\hline
\end{tabular}

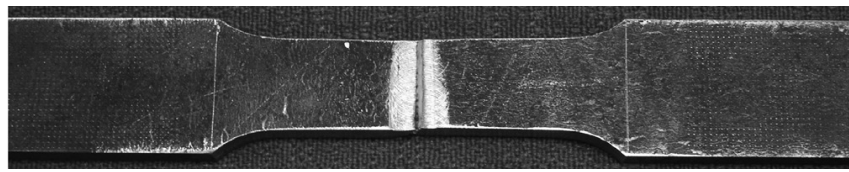

Rys. 7. Złącze ze stali S690QL po próbie rozciągania

Fig. 7. S690QL steel joint after tensile test

Przełom próbki rozciąganej został zainicjowany na brzegu spoiny, w miejscu niewielkiego podtopienia $(0,17 \mathrm{~mm})$, widocznego na rysunku 2.

Próbę udarności wykonano na młocie Charpy'ego o energii początkowej mota $100 \mathrm{~J}$. Zbadana udarność wyniosła $91 \mathrm{KCV} 100 \mathrm{~J} / \mathrm{cm}$. Wygląd próbki po próbie udarności przedstawiono na rysunku 8.

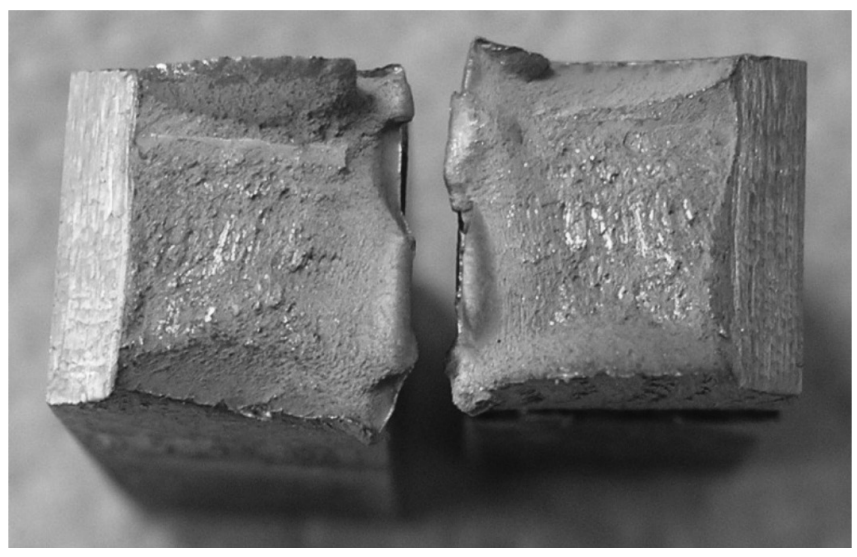

Rys. 8. Widok próbki złącza ze stali S690QL spawanej metodą MAG po próbie udarności

Fig. 8. GMA welded S690QL steel joint after impact test

Przełom próbki jest matowy o cechach materiału plastycznego. Na powierzchni przełomu nie są widoczne niezgodności spawalnicze.
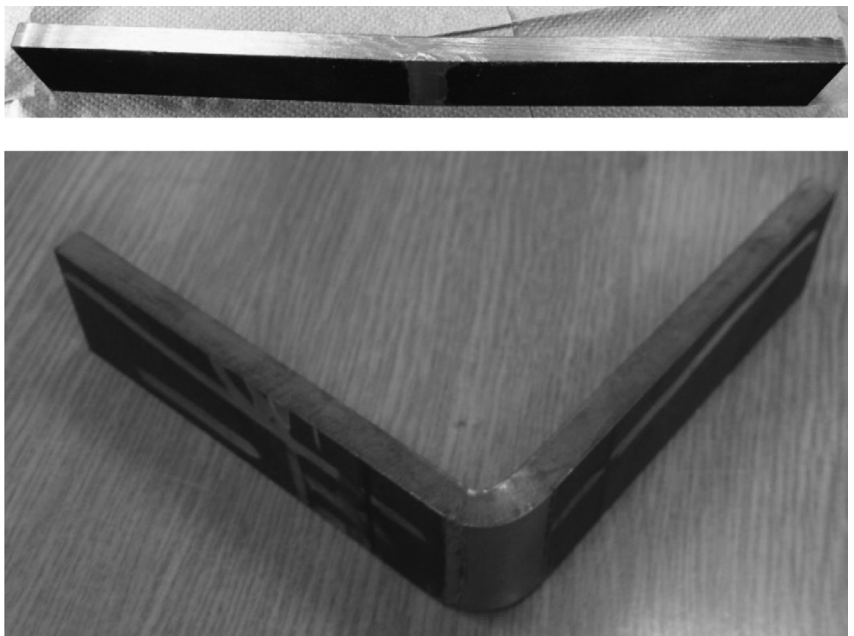

Rys. 9. Próbka przed i po przeprowadzeniu próby zginania

Fig. 9. Specimen before and after bending test

Wg PN-EN ISO 5173:2010 Spawalnictwo - Badania niszczące spawanych złączy metali - Próby zginania, ważny jest dobór średnicy trzpienia gnącego, którą dobiera się w zależności od wydłużenia względne A5. Stale mające A5 $<20 \%$ zgina się do $180^{\circ}$ na trzpieniu o średnicy wyliczanej ze wzoru:

$$
d=t^{*} 100 / A-t
$$

W przypadku stali S690QL, której wydłużenie wynosi 14\% trzpień powinien mieć średnicę $62 \mathrm{~mm}$. Z uwagi na brak takiego trzpienia próbę zginania przeprowadzono na trzpieniu o średnicy $30 \mathrm{~mm}$. Próba była bardzo ostra dla tej stali, a pomimo tego kąt gięcia wyniósł ponad $90^{\circ}$ (rys. 9).

\section{Badania metalograficzne}

Badania metalograficzne wykonano na mikroskopie metalograficznym OLYMPUS K40M. Struktury obserwowano w świetle widzialnym przy powiększeniach 500x na zgładach trawionych odczynnikiem Nital 3\%. Mikrofotografie struktur występujących w badanych złączach spawanych pokazano na rysunkach $10 \div 13$. Materiał rodzimy wykazuje drobnoziarnistą strukturę ferrytyczno-perlityczną z przewagą ferrytu charakterystyczną dla niskowęglowej stali ulepszonej cieplnie (rys. 10). W strefie wpływu ciepła występują dwa obszary struktur, bliższa linii wtopienia wykazuje duży rozrost ziaren od przegrzania stali (rys. 12), natomiast dalej występuje obszar normalizacji stali z wyraźnie widocznym rozdrobnieniem ziaren (rys. 11). Spoina krystalizuje w układzie dendrytycznym o strukturze ferrytyczno-perlitycznej (rys. 13). Nie stwierdzono natomiast występowania twardych struktur martenzytycznych czy bainitycznych.

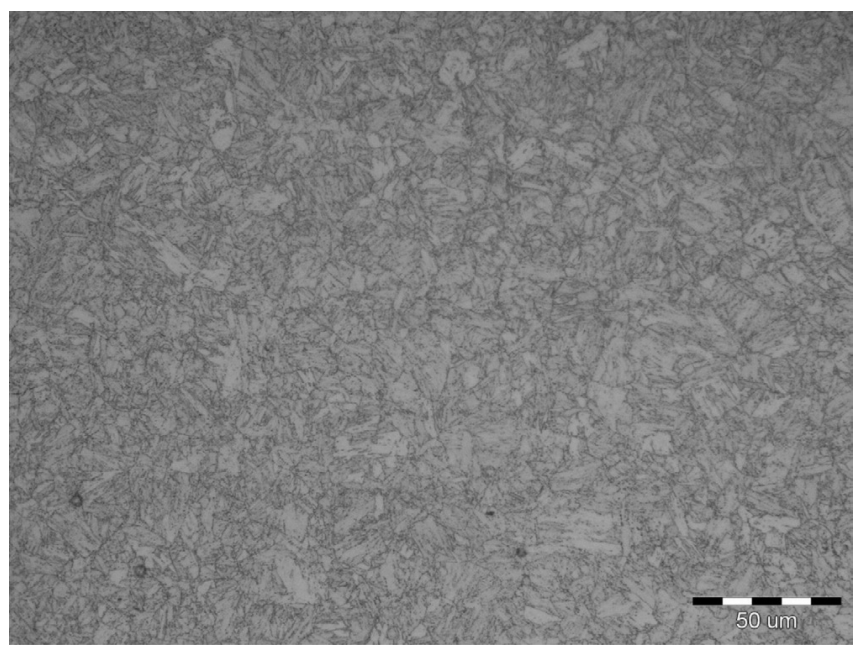

Rys. 10. Mikrostruktura materiału rodzimego stali S690QL

Fig. 10. Microstructure of the S690QL steel as base material

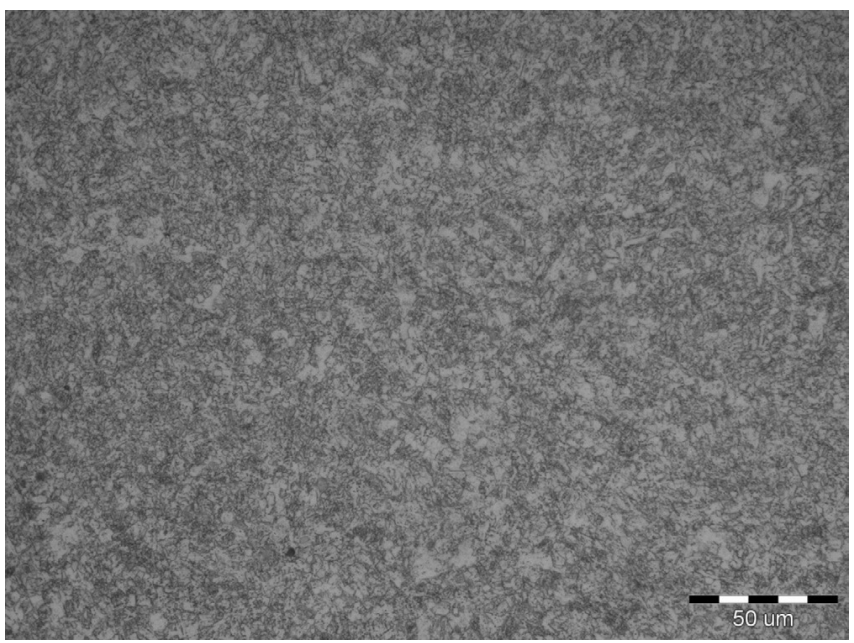

Rys. 11. Mikrostruktura strefy normalizacji pod ściegiem licowym spoiny

Fig. 11. Microstructure of the normalization zone under the face bead 


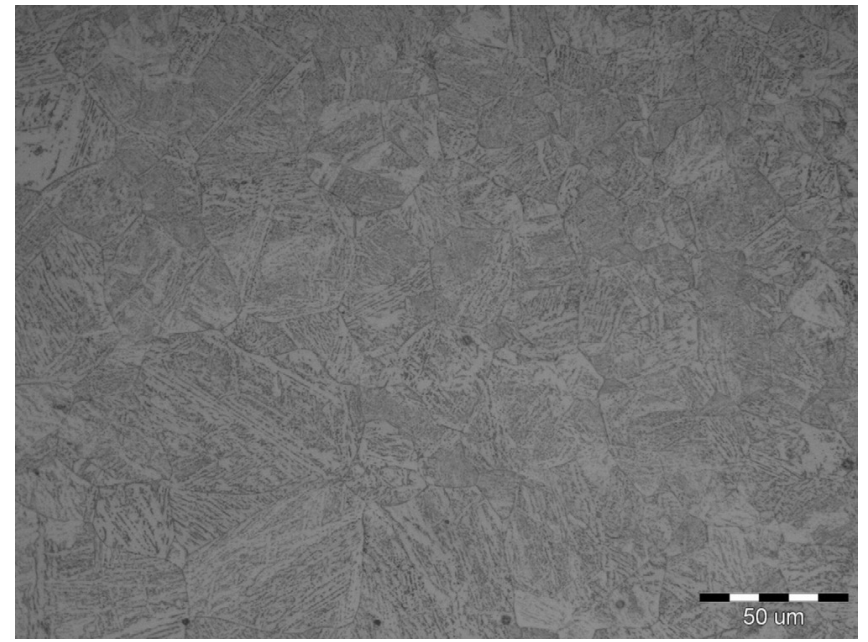

Rys. 12. Mikrostruktura strefy przegrzania SWC spoiny pod ściegiem licowym

Fig. 12. Microstructure of the overheating zone of HAZ under the face bead

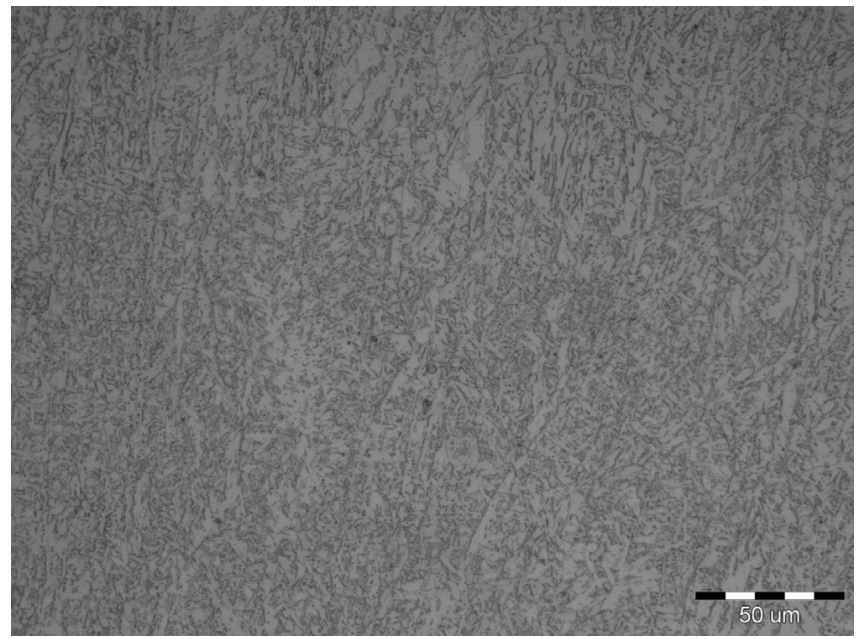

Rys. 13. Mikrostruktura spoiny ściegu licowego Fig. 13. Microstructure of the face bead of the joint

\section{Wnioski}

1. Badania wytrzymałości na rozciąganie wykazały poprawny dobór spoiwa (G $654 \mathrm{M}$ Mn3 Ni1CrMo) do spawania metodą MAG badanej stali S690QL. Wytrzymałość złącza poprzecznego wyniosła $853 \mathrm{MPa}$.

2. Zaostrzona próba zginania złącza poprzecznego (na trzpieniu o średnicy $30 \mathrm{~mm}$, zamiast na $62 \mathrm{~mm}$ ) wykazała kat gięcia ok. $90^{\circ}$ co może świadczyć o jego dobrej plastyczności. Udarność złącza wyniosła $91 \mathrm{KCV} 100 \mathrm{~J} / \mathrm{cm}^{2}$.

3. Pomiary twardości wykazały, że spawanie z odpowiednio dobraną energią liniową badanej stali pozwala na zapewnienie twardości w strefie wpływu ciepła niższej niż 350 HV10 bez obróbki cieplnej przed i po spawaniu pomimo wysokiego równoważnika węgla CEV.

4. Badania makroskopowe ujawniły niewielkie przesunięcia osiowe poszczególnych ściegów. Badania mikroskopowe nie wykazały obecności twardych struktur martenzytu lub bainitu w złączu spawanym.

\section{Literatura}

[1] PN-EN ISO 4136 - Badania niszczące złączy spawanych metali - Próba rozciągania próbek poprzecznych.

[2] PN-EN ISO 9015-1 - Badania niszczące złączy spawanych metali - Badanie twardości - Część 1: Badanie twardości złączy spawanych łukowo.

[3] PN-EN ISO 9016 - Badania niszczące złączy spawanych metali - Badanie udarności - Usytuowanie próbek, kierunek karbu i badanie
[4] PN-EN ISO 5173 - Badania niszczące spoin w materiałach metalowych - Badanie na zginanie.

[5] Mach T.: Spawalność stali ulepszanych cieplnie i własności złączy spawanych. Praca dyplomowa. PWr 2014r. 